\title{
Prótese Parcial Removível Provisória Tipo Overlay na Reabilitação Oral de Paciente com Colapso Oclusal Posterior
}

\author{
Provisional Overlay Removable Partial Denture in Oral Rehabilitation of a Patient \\ with Posterior Occlusal Collapse
}

\author{
YURI WANDERLEY CAVALCANTI ${ }^{1}$ \\ LEONARDO MARCONI CAVALCANTI DE OLIVEIRA ${ }^{2}$ \\ ANDRÉ ULISSES DANTAS BATISTA ${ }^{3}$
}

\section{RESUMO}

Introdução: Nos casos clínicos em que se verifica a diminuição da Dimensão Vertical de Oclusão (DVO) e o desequilíbrio do sistema estomatognático, vários estudos sugerem a reabilitação oral provisória com Próteses Parciais Removíveis (PPR) de recobrimento oclusal (tipo Overlay), associadas ou não com a confecção de restaurações, de modo a recuperar a DVO, restabelecer o plano oclusal e eliminar alterações envolvidas com o desequilíbrio da oclusão, servindo como guia orientadora da reabilitação final. Relato de caso: Este artigo descreve o uso de PPR provisória tipo Overlay na reabilitação oral de paciente do sexo feminino, 56 anos, com colapso oclusal posterior e desgastes dentários excessivos. Essa opção de abordagem foi adotada com o objetivo de preparar o meio bucal e reestabelecer a DVO previamente à reabilitação com próteses definitivas. A sequência de tratamento envolveu os procedimentos de exame clínico e radiográfico, moldagem, determinação estética e funcional dos planos oclusais, através do registro da DVO e da Relação Cêntrica (RC), montagem em Articulador Semi-Ajustável (ASA), provas clínicas e instalação/ajustes. Conclusão: A instalação da PPR provisória do tipo overlay contribuiu para proteção e condicionamento dos tecidos orais, reestabelecimentos das relações intermaxilares, e favorecimento da estética, fonética e função mastigatória. Esses benefícios proporcionaram conforto ao paciente e adaptação do indivíduo à nova configuração do sistema estomatognático.

\section{DESCRITORES}

Prótese Parcial Removível. Revestimento de Dentadura. Dimensão Vertical.

\begin{abstract}
Introduction: Several studies have shown that in clinica cases in which there is a decrease in the Occlusal Vertical Dimension (OVD) and imbalance of the stomatognathic system, oral rehabilitation can be performed with the use of Removable Partial Dentures (RPD) with occlusal coverage (overlay type), associated or not with restorations, in order to reestablish the OVD and occlusal plane and to eliminate occlusion alterations, thus functioning as a guide to final rehabilitation. Clinical case report: This article describes the use of provisional overlay RPD in oral rehabilitation of a female patient, 56 years old, with posterior occlusal collapse and excessive tooth wear. This approach was adopted in order to prepare the oral environment and restore the OVD prior to rehabilitation with final prostheses. The sequence of treatment involved clinical and radiographic examination procedures, tooth casting, aesthetic and functional reestablishment of occlusal planes through the determination of OVD and Centric Relation (CR), cast-mounting in semi-adjustable articulator, prosthesis try-in and insertion, and follow-up. Conclusions: The installation of provisional overlay RPD contributed to protection and conditioning of the oral tissues, reestablishment of inter-maxillary relations and improvement of aesthetic, phonetic and masticatory functions. These benefits provided comfort to the patient and individual adaptation to the new configuration of the stomatognathic system.
\end{abstract}

\section{DESCRIPTORS}

Removable Partial Denture. Overlay Denture. Vertical Dimension.

1 Professor Colaborador do Programa de Pós-Graduação em Odontologia da Universidade Estadual da Paraíba. Departamento de Odontologia. Universidade Estadual da Paraíba (UEPB). Campina Grande - PB, Brasil

2 Professor Associado I da Disciplina de Oclusão e Clínica de Integração. Departamento de Odontologia Restauradora. Universidade Federal da Paraíba (UFPB). João Pessoa - PB, Brasil.

3 Professor Associado I da Disciplina de Oclusão e Clínica de Integração. Departamento de Odontologia Restauradora. Universidade Federal da Paraíba (UFPB). João Pessoa - PB, Brasil. 
A Reabilitação Oral de pacientes parcialmente desdentados é versátil e pode ser realizada através de diferentes opções de tratamento, as quais devem considerar o julgamento profissional, as preferências do paciente, as evidências científicas disponíveis, as necessidades de tratamento odontológico, as limitações biológicas, a higiene oral, a mudança na qualidade de vida, os custos, e as competências técnicas do profissional ${ }^{1-3}$. Nesse sentido, Próteses Parciais Removíveis (PPR) são aparelhos protéticos que podem ser planejados e empregados na recuperação das funções estética, fonética e mastigatória de indivíduos parcialmente dentados, representando uma opção de baixo custo, fácil confecção e amplo acesso da população.

Em grandes reabilitações orais, quando são necessárias intervenções clínicas das diversas especialidades odontológicas, é indicado o uso de PPR Provisórias. A instalação de próteses definitivas deve ser realizada somente após a adequação do meio bucal, quando as necessidades de tratamento odontológico (a exemplo de má higiene oral, doença periodontal, infecção endodôntica, cárie dentária e restaurações imperfeitas) forem sanadas e as estruturas orais estejam preparadas para receber os dispositivos protéticos planejados para conclusão do tratamento reabilitador. Entretanto, é inadmissível que o paciente seja privado da reabilitação parcial das funções orais durante toda a fase reabilitadora do tratamento odontológico. Além disso, a instalação de PPR Provisórias pode contribuir para adaptação do paciente a uma nova condição oral, bem como para o correto relacionamento maxilomandibular, especialmente nos casos de diminuição da Dimensão Vertical de Oclusão ${ }^{4,5}$.

A dimensão vertical da face pode ser representada pela Dimensão Vertical de Oclusão (DVO) e pela Dimensão Vertical de Repouso (DVR). Sendo a dimensão vertical a distância linear entre pontos fixos da maxila e mandíbula, a DVO corresponde na posição de fechamento máximo (máxima intercuspidação), e a DVR, na posição habitual de repouso (posição postural passiva). A diferença entre as medidas DVO e DVR compreende no espaço funcional livre (EFL), ou espaço funcional de pronúncia. Vários estudos consideraram que as alterações da Dimensão Vertical estão intimamente relacionadas com as Disfunções do Sistema Estomatognático e a alteração do relacionamento maxilomandibular pode resultar no aparecimento de sinais e sintomas dessas disfunções ${ }^{6-8}$.

A busca pelo correto relacionamento maxilomandibular é objetivo da reabilitação oral nos tratamentos protéticos. As perdas dentárias apresentam influência direta sobre o desequilíbrio do Sistema
Estomatognático, na medida em que podem acarretar em alterações na mastigação, fonética, estética e na harmonia facial. Além do comprometimento estético e funcional, as relações dentárias, esqueléticas, ou musculares inadequadas também podem acarretar dor, desgastes das estruturas articulares, desgastes dentários e estresses musculares ${ }^{7-9}$.

Em pacientes com a DVO diminuída, observase a redução do terço inferior da face, a projeção do mento, intrusão dos lábios, aprofundamento dos sulcos nasogenianos, perda de estabilidade oclusal posterior, e desgastes dentários por atrição ${ }^{8}$. Nesses pacientes também são observados transtornos fonéticos e mastigatórios, além de possível comprometimento da Articulação Temporomandibular (ATM) e dos músculos da mastigação, semelhante aos quadros clínicos de Disfunção Temporomandibular (DTM). ${ }^{7}$

Para os pacientes nos quais se verifica a diminuição da DVO, vários estudos sugerem a reabilitação oral com Próteses Parciais Removíveis (PPR) do tipo Overlay, associadas ou não com a confecção de restaurações, de modo a recuperar a DVO, restabelecer o plano oclusal e eliminar sintomas dolorosos envolvidos com o desequilíbrio da oclusão $0^{2,5,6,8,10-13}$. A Prótese Parcial Removível Overlay pode ser empregada como tratamento temporário ou definitivo, sendo uma opção de menor custo, maior facilidade de execução, mais rápida e indicada para pacientes com necessidade de recuperação da DVO e realinhamento do plano oclusal. $^{2}$

Alguns autores ${ }^{2,13}$ descrevem a PPR Overlay como uma um dispositivo protético removível que recobre a oclusal de todos os dentes posteriores e as incisais dos dentes anteriores, de modo a oferecer apoio e restaurar a oclusão funcional. A principal indicação da PPR Overlay é o restabelecimento da DVO e do plano oclusal, os quais foram alterados por perdas dentárias, movimentações e desgates. Assim, a PPR Overlay deve funcionar como guia para reabilitação oral do paciente ${ }^{2,6,8,10,11,12,13}$. A PPR Overlay também auxilia na elaboração do diagnóstico, prognóstico, planejamento e execução do tratamento reabilitador, permitindo a avaliação estética e funcional, além da aceitação do paciente antes da realização dos procedimentos clínicos definitivos. $^{2}$

Em casos clínicos complexos, nos quais se verifica a presença de desgastes dentários, inclinações, giroversões, extrusões, migração dentária e alta exigência estética, a reabilitação oral com PPR definitivas só é possível diante de um tratamento clínico integrado com a ortodontia, cirurgia, prótese parcial fixa e implantodontia ${ }^{2}$. Consiste, portanto, uma opção mais invasiva, complexa, demorada e de alto custo. Em 
pacientes com limitações financeiras, baixa exigência estética e presença de limitações médicas ou cirúrgicas, o tratamento com a PPR Overlay representa frequentemente a única alternativa reabilitadora. ${ }^{13}$

Diante disso, o objetivo deste artigo foi relatar o uso de Prótese Parcial Removível Provisória Tipo Overlay na reabilitação oral de paciente com colapso oclusal posterior.

\section{RELATO DE CASO E DISCUSSÃO}

Paciente do gênero feminino, 56 anos de idade, apresentou-se na Clínica Integrada (Dentística, Periodontia, Endodontia e Prótese) do $9^{\circ}$ semestre do curso de graduação em Odontologia da Universidade Federal da Paraíba (Fev-Maio 2011), com queixa de desgaste excessivo dos dentes e comprometimento estético facial. Durante o exame clínico, observou-se desgaste excessivo (esmalte e dentina) dos elementos dentários superiores e inferiores presentes. Os elementos 18, 17, 28, 27, 38, 37, 36, 48, 47 e 46 apresentaram-se ausentes. Os dentes anterossuperiores necessitavam de tratamento endodôntico e o elemento 24 apresentou indicação de exodontia. A oclusão apresentou-se desequilibrada, verificada pela ausência de suporte posterior, colapso oclusal e acentuado desgaste nas faces incisais e oclusais dos elementos superiores e inferiores (Figura 1). Diante dessa condição, a paciente apresentou diminuição da DVO e alterações nas curvas de Spee e Wilson, com inversão do plano oclusal da região anterior.

Após realização da anamnese, exame clínico e radiográfico, realizou-se moldagem das arcadas superior e inferior, utilizando-se alginato (Jeltrate - Dentsply -
Brasil), para posterior obtenção dos modelos de estudo em gesso tipo IV (Durone, Dentsply, Brasil). O modelo superior foi montado em Articulador Semi-Ajustável (ASA) (modelo JP30, Gnatus). Sobre os modelos foram confeccionadas as bases de registro em resina acrílica e cera 07 , que formaram as matrizes das próteses provisórias para o restabelecimento da oclusão do paciente (Figura 2).

Os planos de orientação foram ajustados, iniciando-se pelo plano superior, onde foi ajustado o suporte do lábio, exposição dos dentes em relação ao lábio superior em repouso, e plano posterior, com a utilização da Régua de Fox. Para se realizar o restabelecimento da DVO, utilizou-se uma associação de três métodos de determinação da dimensão vertical, com o objetivo de confirmar a medida obtida para o relacionamento no plano vertical ${ }^{1}$. Sem as bases de registro em boca, dois pontos foram marcados na face do paciente com caneta hidrográfica preta $0,5 \mathrm{~mm}$, sendo um localizado na base do nariz e o outro na região mentoniana, por serem regiões menos influenciadas pela contração da musculatura mímica.

Para se mensurar a Dimensão Vertical de Repouso, através do Método Métrico, foi então solicitado que o paciente realizasse respiração lenta e profunda, umidificando os lábios com a língua, deglutindo e, em seguida, por três vezes, pronunciando a letra “m”, permanecendo ao final desta sequência com os lábios entreabertos e em repouso. Ao observarmos um estável posicionamento mandibular, realizou-se, com auxílio de um compasso de ponta seca, o registro da distância entre dois pontos demarcados ${ }^{1}$

O mesmo procedimento foi repetido por duas vezes e as distâncias observadas eram anotadas. Uma média aritmética destas medidas foi obtida e utilizada

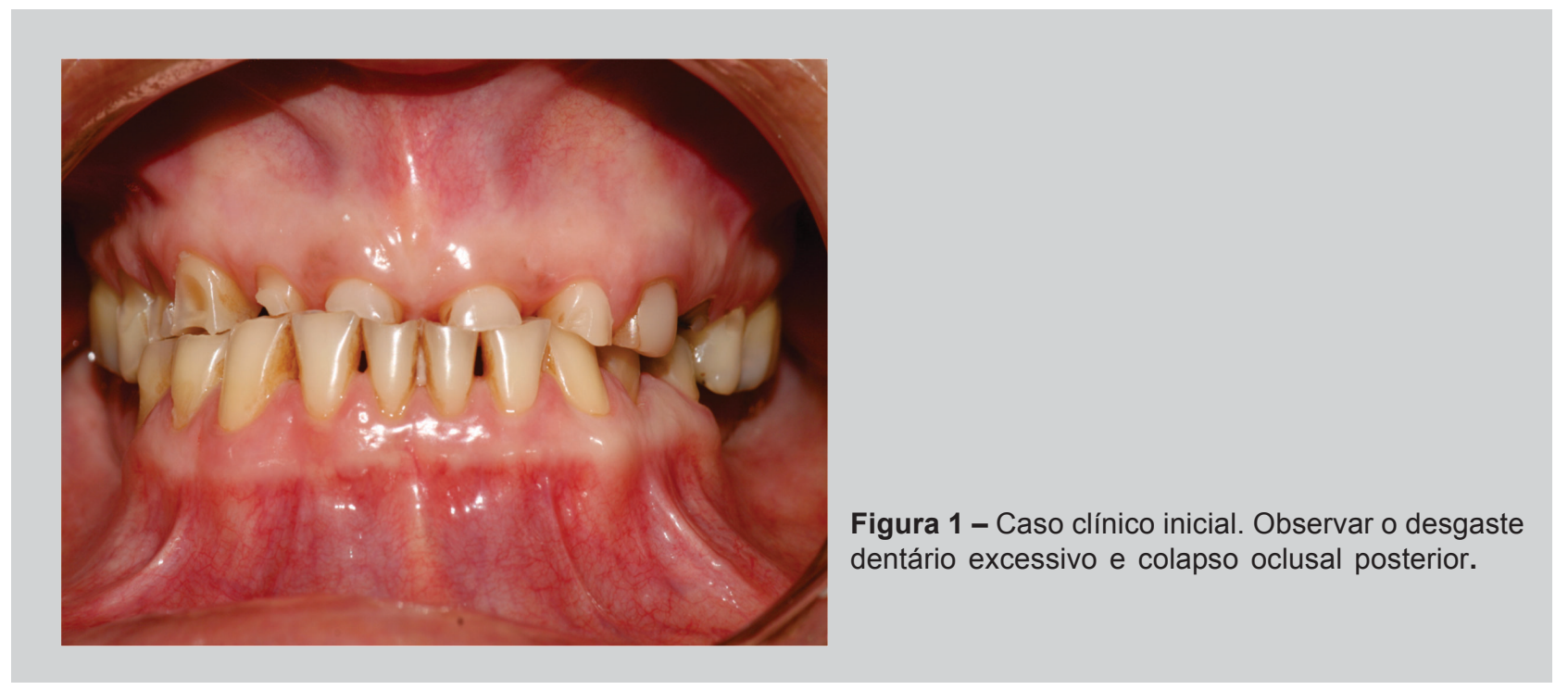


como sendo a Dimensão Vertical de Repouso (DVR). Aplicando a fórmula DVO = DVR - EFL (Espaço Funcional Livre), e considerando-se que o EFL é, em média, de 2 a $3 \mathrm{~mm}$, obteve-se o valor da Dimensão Vertical de Oclusão (DVO). O plano de cera inferior foi então ajustado, pela remoção da cera, adaptando-o ao plano de orientação superior (Figura 3). Quando a DVO adequada foi estabelecida, avaliou-se foneticamente se o EFL estava correto, pedindo ao paciente para pronunciar sons sibilantes ("s"), onde se verificou um EFL satisfatório. A Figura 4 ilustra a diferença entre a DVO inicial do paciente, em máxima intercuspidação (Figura 4A) e a DVO reestabelecida para confecção de PPR provisória do tipo overlay (Figura 4B).

Além dos métodos métrico e fonético, relatados acima, utilizou-se também o método estético, que consiste na reconstituição facial dos pontos de referências por meio da conformação dos sulcos nasogenianos, harmonia do terço inferior com as demais partes do rosto e a obtenção da plenitude facial. As linhas de referência estática (linha média, linha dos caninos e linha alta do sorriso) foram traçadas, e o paciente foi manipulado em relação cêntrica (RC) para realizar o registro da nova DVO. As bases foram unidas e removidas para a montagem em articulador. A cor dos dentes foi selecionada por uma escala de cores adequada (Biotone, Dentsply).

Após a montagem em ASA, realizou-se a montagem dos dentes artificiais nas bases já ajustadas, utilizando para isso dentes de estoque (Biotone, Dentsply). Os dentes superiores e inferiores que se apresentaram desgastados foram recobertos pela base da prótese e dentes artificiais, o que caracteriza uma prótese de recobrimento oclusal ou "overlay" (Figura 5).

Além disso, foi realizado o enceramento da

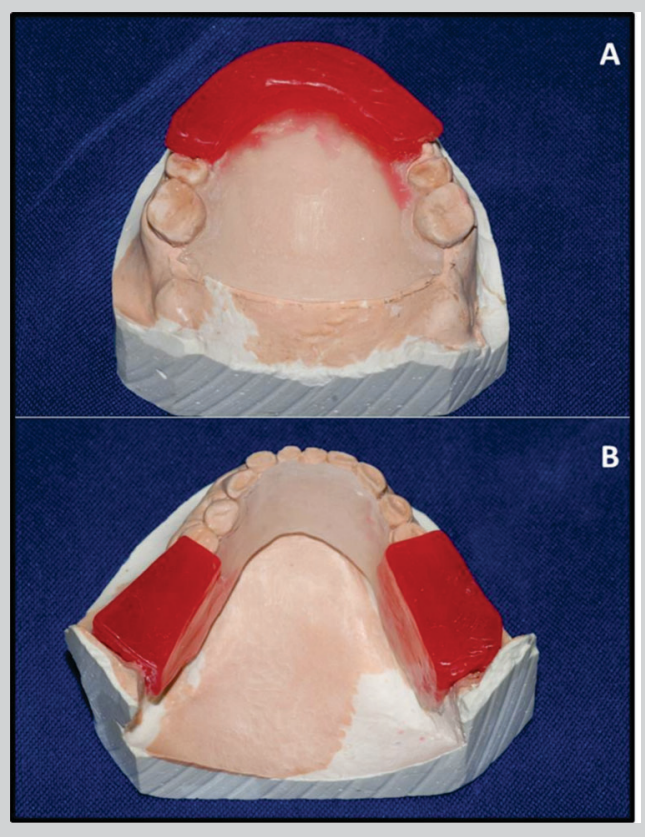

Figura 2 - Bases de registro confeccionadas sobre os modelos de gesso para determinação do relacionamento maxilo-mandibular. A: Modelo superior. B: Modelo Inferior.

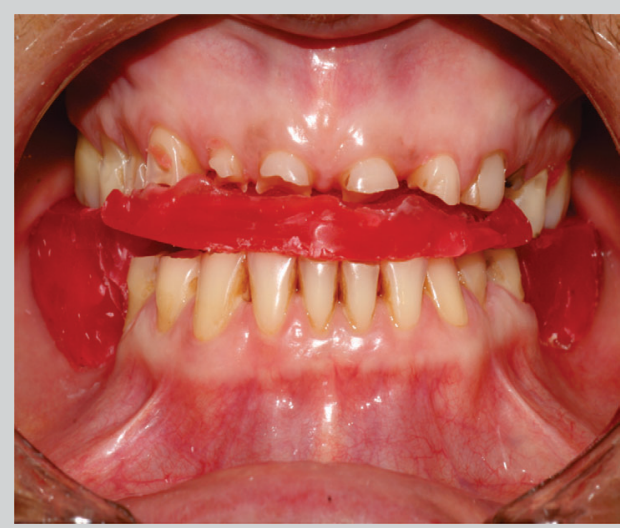

Figura 3 - Planos de cera superior e inferior ajustados após reestabelecimento da Dimensão Vertical de Oclusão (DVO) a partir dos métodos métrico, fonético e estético. 


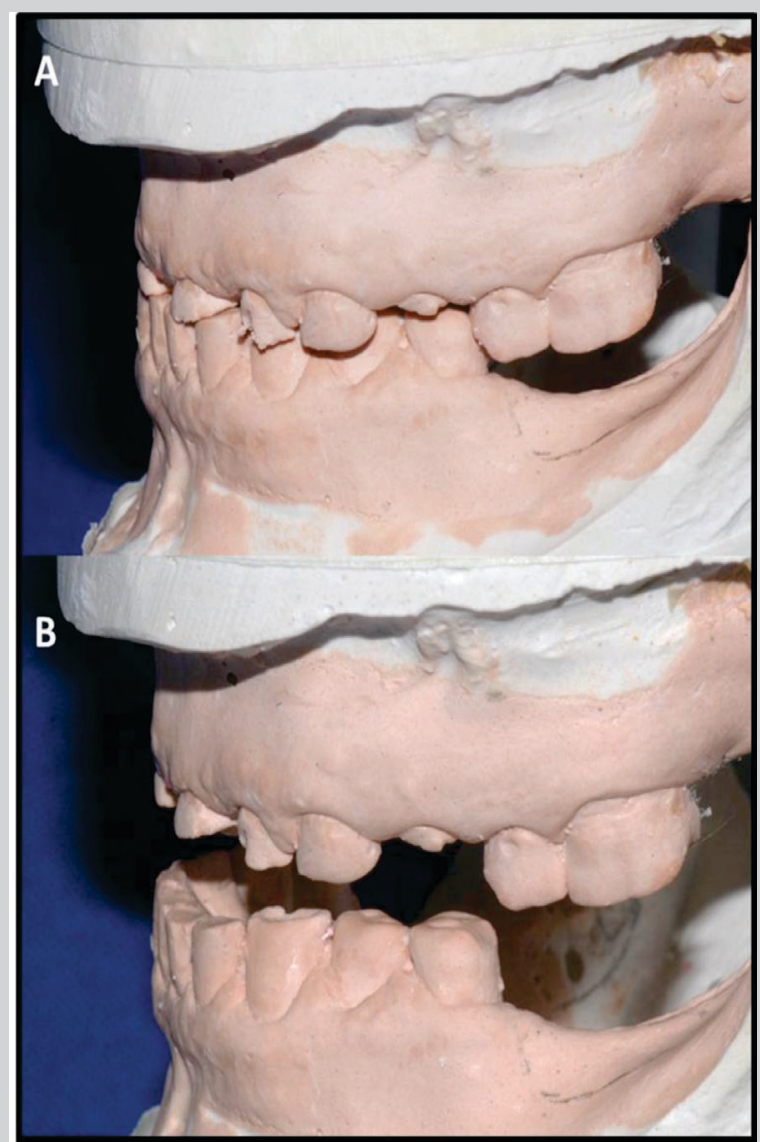

Figura 4 - Distância entre modelos superior e inferior observada na DVO inicial do paciente, em máxima intercuspidação (A) e na DVO reestabelecida para confecção de PPR provisória do tipo overlay (B).

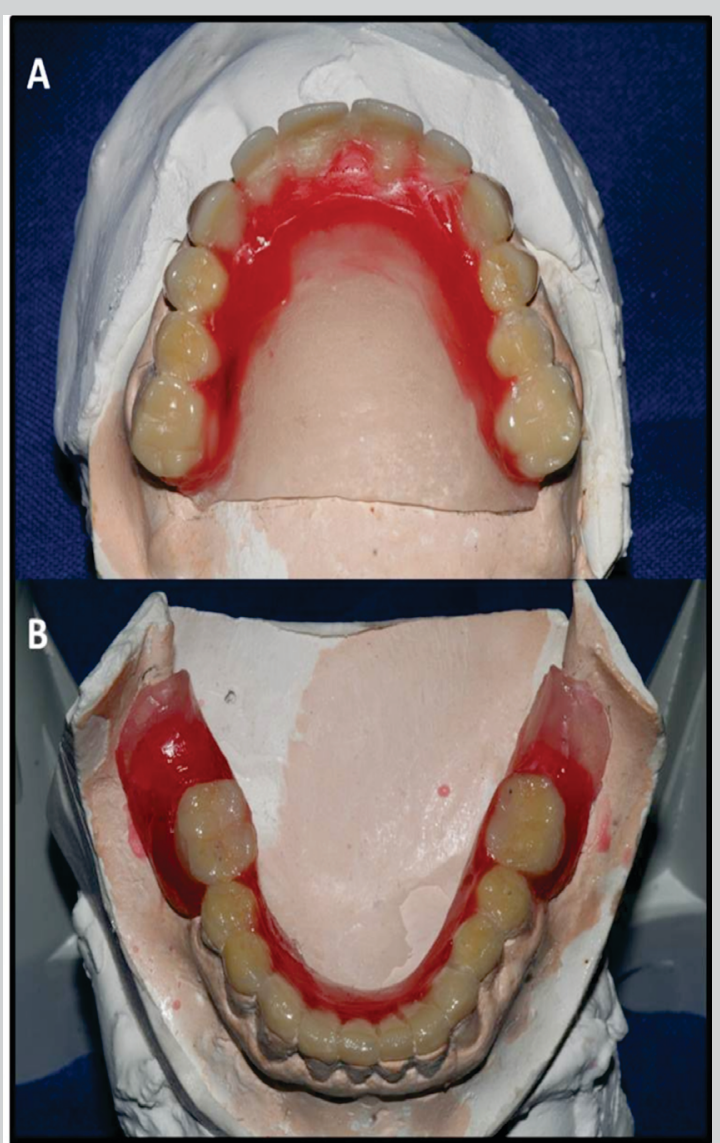

Figura 5 - Montagem dos dentes artificiais sobre as bases de registro superior e inferior para confecção de PPR provisória tipo overlay. Observar recobrimento oclusal e incisal dos dentes superiores e inferiores, o que caracteriza esse tipo de PPR provisória. superfície incisal dos elementos ântero inferiores, que teve como função recuperar a guia anterior, durante os movimentos de lateralidade e protrusão, perdida pelo desgaste incisal, devolvendo a oclusão mutuamente protegida. Após esta etapa, realizou-se a prova dos dentes em boca, observando estética, fonética, oclusão e conforto para o paciente (Figura 6).

A DVO foi conferida, bem como a fonética. Após a aprovação do paciente, realizou-se a inclusão, prensagem e termopolimerização das próteses.

Terminada a fase laboratorial de confecção da prótese parcial removível provisória, procedeu-se a instalação da mesma. Desta forma, restabeleceu-se a DVO (Figuras 7A e B), buscando a estabilidade oclusal, ajustando a mesma tanto em relação cêntrica quanto em lateralidade direita e esquerda.
O paciente foi informado da natureza provisória das próteses instaladas, e necessidade de um tempo de adaptação do organismo à nova DVO, normalmente de 3 a 4 semanas, além do fato da possibilidade do surgimento de pequenas alterações funcionais durante essa fase de adaptação, tais como aumento da salivação, dificuldades fonéticas ou da mastigação dos alimentos. Foi também orientado quanto à forma de higienização das próteses, ao tempo de uso, necessidades de retornos periódicos, até o momento de iniciar o tratamento final com próteses parciais fixas e removíveis. Desta forma, o paciente utilizou estas PPR provisórias até a confecção das próteses finais nos arcos superiores e inferiores. A sequência de tratamento envolveu a realização de tratamento endodôntico e colocação de retentores intra-radiculares nos elementos 


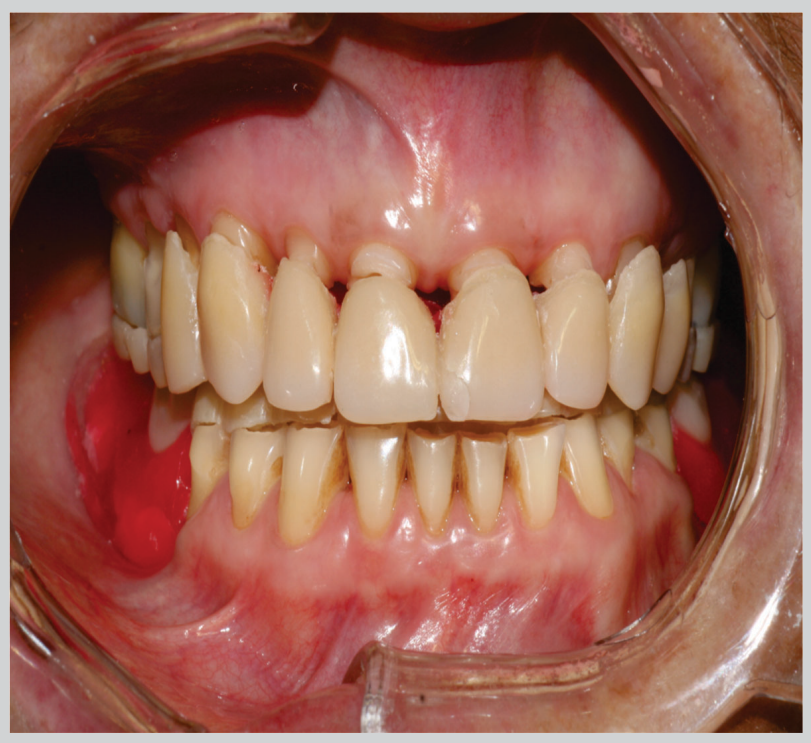

Figura 6 - Prova clínica dos dentes artificiais em boca, observando estética, fonética, oclusão e conforto para o paciente.

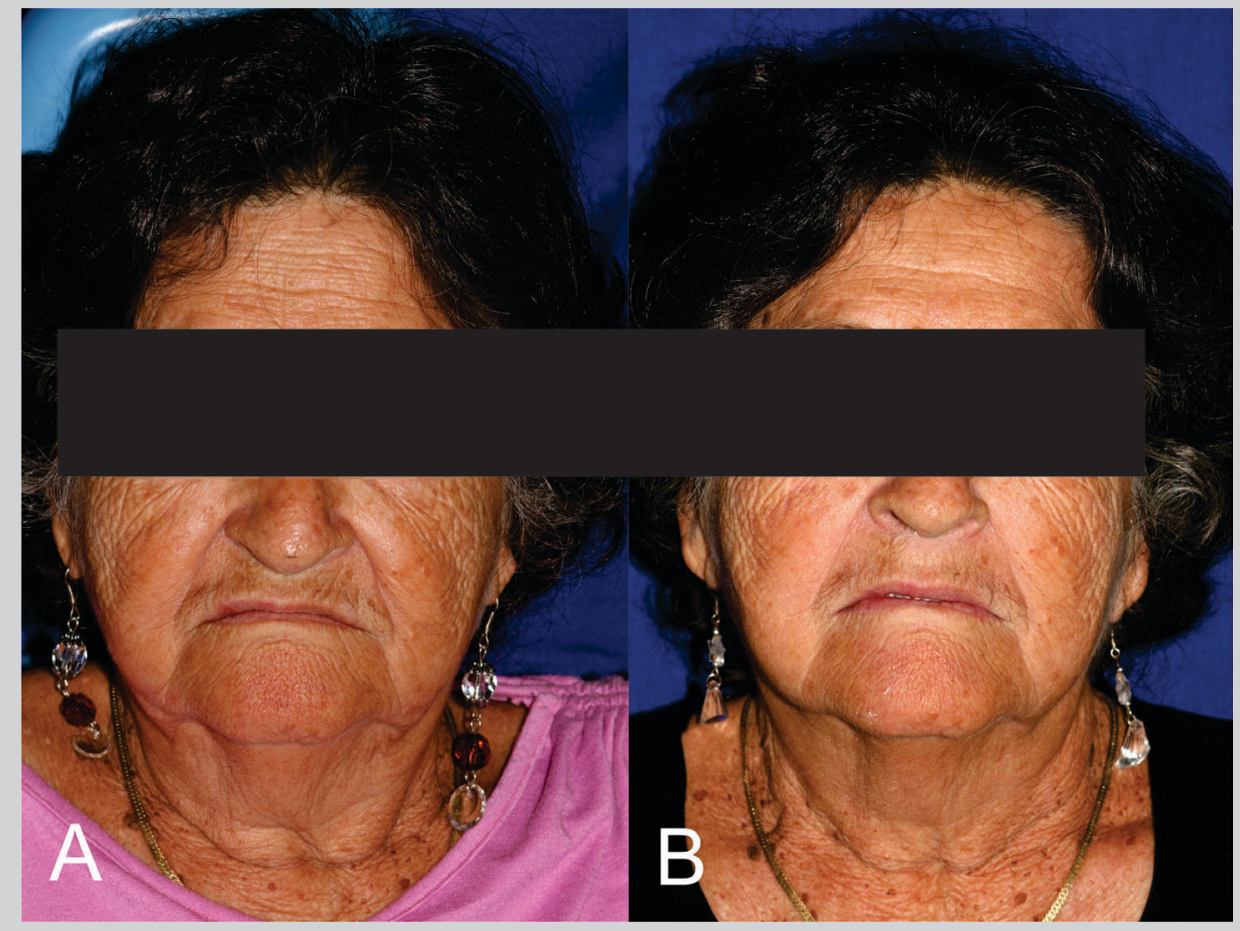

Figura 7 - Vista da estética facial da paciente: (A) Caso inicial mostrando DVO reduzida; (B) recuperação imediata do perfil do $1 / 3$ inferior da face com o uso das PPR Overlay (DVO recuperada). 
anterossuperiores, bem como a posterior confecção de próteses parciais fixas metalocerâmicas unitárias, com exceção do elemento 24, o qual foi reposto por uma PPF de 3 elementos, tendo os elementos 23 e 25 como pilares.

No arco inferior, uma PPR overlay metaloplástica foi confeccionada devolvendo a DVO por meio dos recobrimentos metálicos dos pré-molares. Os elementos anteriores inferiores foram restaurados ao final do tratamento com resina composta fotopolimerizável. Utilizando-se as próteses parciais removíveis provisórias do tipo overlay buscou-se restabelecer integralmente a função, além de contribuir para conforto do paciente e melhorar sua capacidade mastigatória, mantendo a saúde e integridade dos arcos dentais. A utilização destas PPR é de suma importância, pois existe a possibilidade de ao final do tratamento o paciente não se adaptar à nova DVO, o que acarretará ao insucesso do tratamento reabilitador. $\mathrm{O}$ uso das próteses de recobrimento oclusal permite uma adaptação progressiva à nova DVO, o que facilita a resolução de possíveis problemas funcionais.

Semelhante ao presente relato de caso, outros autores obtiveram sucesso e relataram a utilização de PPR de recobrimento oclusal para reabilitação de pacientes com DVO diminuída, colapso oclusal posterior, desgaste dentário severo e ausência dos dentes posteriores, $2,8,10-13$.

Os benefícios da escolha da PPR Overlay como opção de tratamento para esse grupo de pacientes se encontra no menor custo, maior facilidade de execução, menor limitação biológica, e reversibilidade do caso $^{2,10-}$ ,13. A instalação de PPR Overlay permite que o paciente recupere mais rapidamente a DVO, a harmonia facial, e a eficiência mastigatória, sendo também capaz de manter a condição oral reabilitada ${ }^{10-13}$.

Como desvantagens do uso da PPR Overlay, vários estudos destacaram o comprometimento estético, desconforto temporário, necessidade de adaptação e aceitação do paciente, necessidade de adequada higienização oral2,13.

Conforme observado em outros estudos, o tratamento descrito neste relato de caso alcançou o restabelecimento de padrões aceitáveis de estética, função, mastigação e conforto, sendo possível recuperar a harmonia facial satisfatória e a DVO ${ }^{10-12}$.

\section{CONCLUSÕES}

Diante do caso clínico relatado, verifica-se que as PPR provisórias desempenham papel relevante no tratamento integrado, na medida em que contribuem para recuperação das funções orais e maior previsibilidade dos casos clínicos. A instalação da PPR provisória do tipo overlay contribuiu para proteção e condicionamento dos tecidos orais, reestabelecimentos das relações intermaxilares, e favorecimento da estética, fonética e função mastigatória. Esses benefícios proporcionaram conforto ao paciente e adaptação do indivíduo à nova configuração do sistema estomatognático.

\section{REFERÊNCIAS}

1. Bonachela W, Telles D. Planejamento em Reabilitação Oral com Prótese Parcial Removível. São Paulo: Santos. 1998. $85 p$.

2. Souza JEA, Silva ET, Leles CR. Prótese Parcial Removível Overlay: fundamentos clínicos e relatos de casos. ROBRAC. 2009; 18(47): 41-8.

3. Batista AUD, Sales JPLA, Farias Neto A, Carreiro AFP. Avaliação do Planejamento de Prótese Parcial Removível em Modelos Recebidos por Laboratórios de João Pessoa, PB. Pesq Bras Odontoped Clin Integr. 2011; 11(1): 53-8.

4. Goyatá FR, Thomé EMOS, Brum SC, Oliveira RS, Ferreira TFRZ. Tratamento restaurador multidisciplinar - relato de caso clínico. Int J Dent. 2008; 7(2): 142-65.

5. Silva MCCS, Carreiro AFP, Bonan RF, Carlo HL, Batista AUD. Reabilitação Oclusal com Prótese Parcial Removível Provisória Tipo "Overlay" - Relato de Caso. R Bras Ci Saúde. 2011; 15(4): 455-460.

6. Dekon SFC, Pellizzer EP, Zavanelli AC, Ito L, Resende CA. Reabilitação oral em paciente portador de parafunção severa. Rev Odontol de Araçatuba. 2003; 24(1): 54-9.

7. Farias ABL, Lima LHMA, Costa LJ, Lucena LBS, Farias $A B L$. Relação entre alteração da dimensão vertical de oclusão e disfunção temporomandibular - avaliação clínica. Braz Dent Sci. 2009; 12 (3): 11-9.

8. Rodrigues RA, Bezerra PM, Santos DFS, Duarte Filho ESD. Procedimentos multidisciplinares utilizados na recuperação da DVO durante a reabilitação estética e funcional - relato de caso. Int J Dent. 2010; 9(2): 96-101.

9. Feltrin PP, Philippi AG, Moretti Junior J, Machado CC, Astolf JA. Dimensões verticais, uma abordagem clínica: revisão de literatura. Rev Odontol Univ Cid Sao Paulo. 2008; 20(3): 274-9.

10. Fragoso WS, Troia Junior MG, Valdrighi HC, Chiavini $P$ Oliveira PA. Reabilitação Oral com Prótese Parcial Removível Overlay. RGO. 2005; 53(3): 243-6.

11. Cura C, Saraçoðlu A, Oztürk B. Prosthetic rehabilitation of extremely worn dentitions: case reports. Quintessence Int. 2002 ; $33(3): 225-30$. 
12. Freitas R, Kaizer OB, Pigozo MN, Cavallari P, Resende DRB. Diagnóstico e Tratamento da Dimensão Vertical de Oclusão Diminuída. RGO. 2007; 54(2): 161-4.

13. Patel MB, Bencharit S. A Treatment Protocol for Restoring Occlusal Vertical Dimension Using an Overlay Removable Partial Denture as an Alternative to Extensive Fixed Restorations: A Clinical Report. Open Dent J. 2009; 3(30): 213-8.

\section{Correspondência}

Yuri Wanderley Cavalcanti

Rua das Baraúnas, 351

Departamento de Odontologia.

Universidade Federal da Paraíba.

Campina Grande -PB - Brasil. CEP: 58429-500.

E-mail: yuri.wanderley@yahoo.com.br 